\title{
ERRATUM
}

\section{Plasmonics for extreme light concentration and manipulation}

Jon. A. Schuller, Edward S. Barnard, Wenshan Cai, Young Chul Jun, Justin S. White and Mark L. Brongersma

Nature Materials 9, 193-204 (2010); published online: 19 February 2010; corrected after print: 5 March 2010.

In all versions of this Review originally published, the upper part of Fig. $2 \mathrm{c}$ should have appeared as shown.

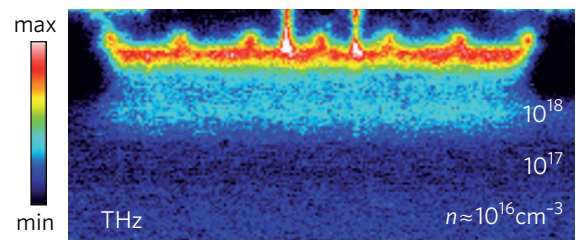

This has been corrected in the PDF and HTML versions of this Review. 